\title{
Physical and Physiological Problems of Medical Monitoring
}

\author{
K. M. Lebedinskii ${ }^{a, b, *}$, A. N. Kovalenko ${ }^{c}$, I. S. Kurapeev ${ }^{a}$, A. E. Karelov ${ }^{a}$, \\ A. I. Len'kin ${ }^{a}$, V. V. Subbotin ${ }^{d}$, P. A. Volkov ${ }^{e}$, and D. V. Martynov ${ }^{\prime}$ \\ ${ }^{a}$ North-Western State Medical University Named after I.I. Mechnikov, St. Petersburg, 193015 Russia \\ ${ }^{b}$ Federal Research and Clinical Center of Intensive Care Medicine and Rehabilitology, Moscow, 107031 Russia \\ ${ }^{c}$ Ioffe Institute, St. Petersburg, 194021 Russia \\ ${ }^{d}$ Loginov Clinical Scientific Applied Research Center, Moscow Health Department, Moscow, 111123 Russia \\ ${ }^{e}$ AO Klinika K+31, Moscow, 119415 Russia \\ ${ }^{f}$ Rostov State Medical University, Ministry of Health of the Russian Federation, Rostov-on-Don, 344022 Russia \\ *e-mail:mail@lebedinski.com \\ Received February 3, 2020; revised February 3, 2020; accepted February 17, 2020
}

\begin{abstract}
This review discusses physiological, engineering, ergonomic, cognitive, and economic aspects of medical monitoring, which is among the most rapidly developing and sophisticated areas of medicine and medical engineering in the current historical context. A particular emphasis is laid on clinical requirements for monitoring, monitors, and monitored parameters, as well as challenges and debatable and problematic aspects of monitoring, including interpretation of physiological signals, the impact of monitoring on treatment outcomes in patients, challenges in designing automated systems for controlling the physiological functions of a patient based on monitoring data, and monitoring of the integrative assessment of the state of the human body as a complementary and sometimes more effective alternative to conventional "analytical" types of monitoring of particular physiological functions and parameters.
\end{abstract}

DOI: $10.1134 / \mathrm{S} 1063784220090212$

\section{INTRODUCTION}

\section{Mission and Objectives of Medical Monitoring}

Monitoring is a continuous observation over the period of time of a process or parameter on a real-time basis [1]. Satisfying these two temporal conditions allows not only a one-off measurement, but also tracking trends in the progression of events, on the one hand, while the derived data captures the current state of a monitored object at any particular time, rather than reflecting the past.

In English, according to the American Merriam-Webster Dictionary (1993) [2], the verb "to monitor" has been used meaning "to watch, keep track of, and check usually for a special purpose" since 1924. In Russian, the first use of the word "monitor" in the meaning of "control device" dates back to October 21, 1957, when, two weeks after the launch of the first artificial satellite, the Pravda newspaper wrote about a "neutron monitor" [3]. The family of words built on the root "monitor" originate from the IndoEuropean root element "men-," "to think," and its derivatives referring to various states and qualities of mind and thought (e.g., "mental," "dement," etc.) [4]. The Latin verb "moneo," the etymology of which traces from the noun "mens" ("mind, reason, thought, opinion") in the Latin-Russian Dictionary of I.Kh. Dvoretskii [5] gives meanings a number of which are consonant with the modern role of monitoring, that is, "napominat', obrashchat' vnimanie, predosteregat', preduprezhdat'; vnushat', nastavlyat', ukazyvat'; predveshchat', predskazyvat" ("remind, pay attention; warn, caution; admonish, instruct, point; preview, predict"). Meanings additionally listed thereon include "tot, kto napominaet; sovetnik, konsul'tant ( $v$ sudebnom protsesse); tot, kto predosteregaet, preduprezhdaet; nadziratel', nadsmotrshchik" ("one who reminds; adviser, counselor (in court); one who warns and cautions; warden, overseer").

Medical monitoring is nearly as old as medicine itself; it is as natural to monitor a patient in the course of medical treatment as to perform the latter. The entire history of medicine is closely related to advances in diagnostic methods and instrumental tools and the prediction of health conditions based on the physiological parameters of body functioning. They can be revealed through a variety of thermal, mechanical, electric, chemical, and other biological signals recorded in medical monitoring systems both in the form of directly measured physical quantities (temperature, pressure, bioelectric potentials, etc.) and as indicators characterizing the interaction of a body with external physical fields (quantity of attenuation of ultrasound, electromagnetic waves, optical radiation, 
etc., travelling through examined tissues). Depending on physical nature of the signal and need for the processing, the data can be perceived by medical staff both via various devices (monitors) and directly by the senses (vision, hearing, touch, etc.). Correct medical interpretation of the measured quantities and visualization of medical image data as a result of exposure of a body to fields requires a thorough understanding of both the physiological and physicotechnical fundamentals, which are the keystones of techniques for obtaining and processing the signals used by the instruments. The physiological basis of all biological signals in a body is determined by metabolic processes in the way of a set of biochemical reactions of metabolism of organic and inorganic compounds for their use as a source of energy to sustain life with enzyme "self-regulation" of their kinetics on the side of the nervous and endocrine system of the body depending on conditions of external environment and internal factors. The behavior of these processes is governed by the same universal laws of thermodynamics and their specific physical-chemical terms, describing heat and work conversion in the body as in an open system, which exchanges matter and energy with the surroundings. This provides the foundation for the techniques for receiving and processing the signals, as well as for the development of the essential instruments and devices. Parameters to control are selected from the entire set of possible parameters based on the purposes of medical observation, namely, the initial exam, follow-up care, specialized control during treatment of detected disease, and first aid and emergency care in the extreme conditions, including continuous on-line monitoring of essential vital signs in critical conditions with severe dysfunctions of the body's vital systems. The latter primarily include the cardiovascular and respiratory, as well as regulatory and excretory, systems, impairment of which at the terminal progression with worsening hypoxia of cerebral cortex is highly likely to cause a fatal outcome and requires urgent restoration with the involvement of resuscitation procedures in resuscitation and intensive care units.

Today, continuous presence of appropriately trained staff during administering and management of anesthesia has been a key component of any monitoring standard dating back to the first standards at Harvard [6]. As early as in the mid-19th century, advancement in clinical practice, surgical and emergency care in the first place, brought about a need for real-time monitoring of a patient's objective physiological parameters. Thus, the "first anesthetic practitioner," John Snow (1813-1858), palpated the pulse continuously during anesthesia, while the prominent neurosurgeon Harvey W. Cushing (1869-1939) introduced anesthesia chart to record parameters of respiration and circulation [1]. Simple adaptation for use of common objects and instruments facilitates monitoring of complex physiological functions, ranging from cotton moustaches on the upper lip to observe the respiration of a patient to a stethoscope connected to a gastric catheter in the esophagus to listen to the sound of the heartbeat without interference.

The advancement in monitoring of the oxygen transport chain is of particular interest, inasmuch as hypoxia remains a problematic area in critical care medicine. Visual observation of cyanosis has become a starting point - that is, skin and mucosa acquires a bluish (or grey in Africans) shade at concentration levels of deoxygenated hemoglobine $\mathrm{Hb}$ of at least $50 \mathrm{~g} / \mathrm{L}$, methemoglobin MetHb more than $15 \mathrm{~g} / \mathrm{L}$, and sulfhemoglobin $\mathrm{HbSO}_{4}$ more than $5 \mathrm{~g} / \mathrm{L}$ [7], which allows for application of spectroscopic methods for real-time recording of the oxygen saturation of hemoglobin and detection of hemoglobinopathies. As early as in 1933, in Germany, Karl Matthes (19051962) invented the first percutaneous optical oximeter, operating in the red and infrared spectral regions similarly to the modern pulse oximeters [8]. In 1942, the American physiologist Glen A. Millikan (19061947), son of the prominent physicist Robert A. Millikan (1868-1953), designed for the Royal Air Force two wavelengths hemoximeter with a pilot earlobemounted sensor equipped with red and green light filters. When high-altitude hypoxemia approached a critical level, the device issued a warning with a sound signal, while the aircraft Bendix oxygen system automatically began deliver oxygen under the face mask [9]. A similar oximeter was designed in the Soviet Union in 1944 by the physiologist E.M. Kreps (18991985) and engineers M.S. Shipalov, E.A. Bolotinskii, and A.G. Kreitser and was mass-produced by the Leningrad Krasnogvardeets factory [10]. In 1951, R.C. Steven, H.M. Slater, and A.L. Johnson employed the Millikan oximeter in an operating room [11], and Soviet anesthesiologists used the national mass-produced recording oximeters ("oxyhemographs") O26, O36, and O57 [12] (Fig. 1). In 1975, a major breakthrough was made by the Japanese researcher Takuo Aoyagi, who studied spectroscopic dye dilution curves in blood. Pulsations of arterial flow that were first combatted were later put into service as a useful signal: naturally, the flow pulsates only in arterioles. Therefore, spectroscopy of a pulsatile component of the flow reflects arterial blood composition the most accurately. In the late 1970s, Scott Wilbur, who was at Biox, invented a compact sensor incorporating two emitting photodiodes and one receiving photodiode, which represented a divergence from the fibrooptical cables of Aoyagi's pulse oximeter, while the introduction of intelligent signal processing by Biox and Nellcor in the early 1980s finally and conclusively made the oximeter the routine and ubiquitous monitor that it is known as today [8]. The 21st century has seen a spread of percutaneous near-infrared tissue (including the cerebral) oximetry and multiwavelength COoximetry (Rainbow, Massimo, United States), making it possible to estimate the concentration of blood 
total hemoglobin and its fractions [13, 14], which, however, requires improvements in accuracy and resistance to sources of interference [15].

\section{PRINCIPLES OF CLASSIFICATION AND REQUIREMENTS FOR MEDICAL MONITORING}

It is possible to monitor any process that unfolds continuously in time. Monitoring, however, is necessary if the delay in information leads to considerable losses of data and effectiveness of medical treatment. The more dynamic the processes, the more aggravated the consequences due to the "gap" in events, and the more effective the possibilities to manage their progression, the greater the need for monitoring [1].

In terms of the monitoring perceived as a tool of patient's safety available to medical practitioner, consider the concept of critical incident (CI) introduced to anesthesiology by Jeffry Cooper in 1974. The CI is an occurrence of "... human error or failure of equipment, which (if not discovered or corrected in time) could have led, or did lead, to adverse consequences ... to death" [16]. Not every CI becomes a complication; the chain of events in progression of complications through the way of CI can be presented as follows: incident (event with a low risk of harm infliction), critical incident, reversible undesirable outcome, complication, and, finally, irreversible complication, including fatal outcome. The lower the frequency of CI occurrence, the more advanced the safety system.

From this standpoint, monitoring plays a key role as a tool in detecting and recording CIs. Nevertheless, the mere detection and recording of CI is insufficient for ensuring a patient's safety, inasmuch as, when "not corrected in time," CI causes complications. Center stage is then taken by the issue, on which we elaborate below, that it is the personnel and not the monitor who makes a decision regarding medical treatment.

A substantial fraction ( $83 \%$ according to a number of authors) of CIs and complications is due to human error [17]. People tend to underestimate or hide their errors; therefore, monitoring is vital. This was confirmed by the study of A.K. Jha et al. (1998), in which doctors reported only $4 \%$ of undesirable events associated with medications out of the $45 \%$ revealed by the monitors [18].

Monitoring aims at improvement of safety and quality of the process management [1] achieved by means of

(a) proactive (preventable) correction of negative trends (elimination of $\mathrm{CI}$ );

(b) prediction of abnormal and harmful situations;

(c) instant reporting on the development of events should such a situation occur;

(d) differentiation of pathogenetic mechanisms of their progression;
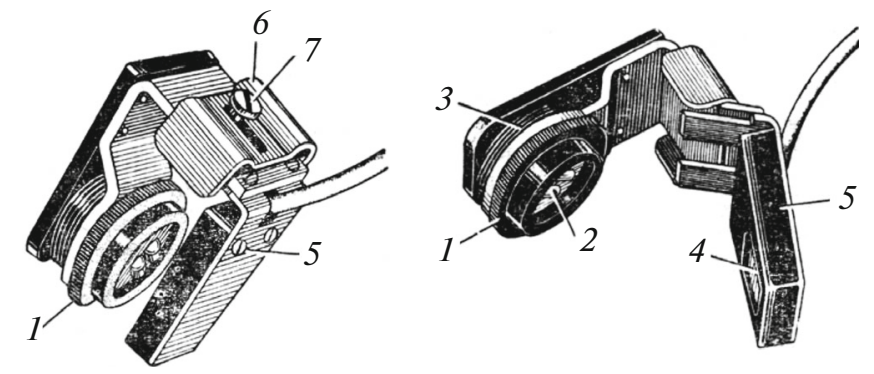

Fig. 1. Sensor of the O36M Soviet oxyhemograph (Krasnogvardeets, Leningrad) in a closed (left) and open (right) state [10]: (1) tube, (2) photoconverters, (3) bearing, (4) sensor body window, (5) photoelectric case, (6) clip, and (7) screw.

(e) feedback provision in the process of management;

(f) possibility of the safe use of comprehensive facilities [19]; and

(g) documenting the array of data for finding solutions to different tasks.

Importantly, the large number of cases will not allow for an all-in-one solution to the aforementioned objectives. Thus, pulse oximetry and capnography (monitoring of the $\mathrm{CO}_{2}$ concentration in the respiratory gas mixture during inspiration and expiration) are perfect when acting as a universal warning bell (item c), whereas these methods do not generate enough information to differentiate between various mechanisms of damage to the respiratory (item d).

The monitoring should satisfy a wide range of clinical requirements, the most universal among which can be summarized as follows [1]:

(1) the rationale, that is, the presence of sufficient grounds to consider a specific type of monitoring justified (medically necessary) in the situation at hand for this particular patient at a current level of development of natural history and medical science;

(2) purposefulness, that is, a focus, first, on the solution of specific clinical tasks to provide for a patient's safety, in particular, and, second, on receiving the information most important in this particular case;

(3) veracity and accuracy, that is, conformity of the received information with the actual with the maximum closeness of measurements to "true" values of monitored parameters;

(4) continuity, that is, elimination of gaps in tracking the situation that can result in the sudden, for a medical practitioner, occurrence of a threatening situation or lead to a misunderstanding of the causes of the events due to poor awareness about their time course;

(5) action, that is, proactive use in solving monitoring tasks of all resources, including uncommon ones, as dictated by the circumstances; 
(6) minimally invasive procedure, that is, reduction of medical and legal risks associated with the monitoring procedure proper to the necessary minimum sufficient for solving its clinical tasks; and

(7) clinical and economic effectiveness, that is, necessary equipment and consumables financially affordable by a health facility and the absence of less costly alternatives producing the similar clinical outcome.

Interestingly, the aforementioned largely (2-5) coincide with the requirements for the combat support branches, e.g., intelligence [20], which, in essence, is a kind of situation monitoring.

What exactly should be monitored in a clinic? J.B. Hall (2005) [21] formulates the following criteria that should be met by the physiological parameter to qualify for an object to be monitored in critical care medicine: perturbations in the given measurement in the course of illness should have a sound pathophysiologic rationale; the parameter should be comprehensible in terms of reliable measurement under typical conditions; the parameter should offer information not available from more routine methods of monitoring and interventions should exist, which can influence the monitored variable; and titrating therapy based on this parameter should have a positive effect on treatment outcomes.

Today, it has become fashionable to formulate an idea of an "ideal drug," "ideal method," "ideal device," etc. According to G. Satkurunath, A. Rhodes, and M. Cecconi (2009) [22], an "ideal monitor" should be able to produce accurate and reproducible (precise) data, be of use to a clinician, improve outcomes in patients, not be costly and be straightforward with respect to data use and interpretation, be free of unnecessary risk, be easy to transport, be low-maintenance, be free from artifacts, and be and equipped with alarms to signal a need for immediate intervention.

Notwithstanding the value of all the aforementioned, let us an important limitation. A monitor alone, no matter how advanced, cannot influence treatment outcomes and produces effects through the intermediary of the staff personnel who makes and implements a decision, rather than by direct exposure to it by a patient. A clear exception to this appears to be the complexities of the monitoring proper. This issue, in terms of the impact of monitoring on outcome, has manifested itself most remarkably in debates on pulmonary artery catheterization. A proper formulation of the problem and associated task appears to be something like "the effective monitor should supply personnel with information that, assuming that there is a correct and uniform interpretation, can ensure that timely strategic decisions are made and actions taken that can influence treatment outcomes positively" [1].

Medical monitoring is classified based on the target of interest (physiological function and physical or chemical parameter, such as monitoring respiration, hemodynamics, neuromuscular transmission, metabolism, oxygen saturation of hemoglobin, body temperature, etc.); physical nature of a physiological signal (optical, mechanical, thermal, electrophysiological, etc.) and its character (spontaneous or induced: compare measurement of the body temperature with the analysis of thermodilution curve recorded from the catheter in pulmonary artery or electrocardiography with impedance cardiography, native electroencephalography and somatosensory evoked potentials, etc.); on the basis of specific characteristics and variations in its processing (the organoleptic, computer, trend recording, etc.); and, finally, by degree of invasiveness [1]. A transition from invasive procedures (e.g., catheterization of the pulmonary artery) to minimally invasive (transesophageal echocardiography) or noninvasive (photoplethysmographic cardiac output) analogs is a modern trend.

Note that there is something else that can serve as a basis for classification of monitoring technologies from the cognitive perspective. There are universal monitors that, to a greater or lesser degree, will initiate an alarm (such as a pulse oximeter, capnograph, detector of bubbles in artificial blood circuits, etc.) and monitors that serve as measuring instruments (for example, a Swan-Ganz catheter in the pulmonary artery or an accelerometric monitor of neuromuscular transmission). The latter type of monitor gives rise to a greater number of questions in terms of their impact on treatment outcomes.

To summarize what has been covered, the role of monitoring as a tool of documenting the events should not be overlooked. In many cases, it is objectively recorded data that allows a definite opinion to be formulated regarding the issue at hand and the sequence of events that have taken place during an anesthetic or resuscitation procedure. Regretfully, this type of information is not always supportive of doctor's actions and can result in administrative and criminal cases [23]. There is little doubt, however, that, in the future a concept of a "black box" that would record the dynamic series of all monitored parameters and, probably, voice conversations between the staff and the patient will be adopted in a medical context. At present, all emergency rooms in Europe are equipped with video surveillance cameras, and the footage is kept for at least the ensuing $24 \mathrm{~h}$. Should a conflict arise, which occurs commonly in the dramatic setting of emergency medical care, the videoprotocol will be on the side of conscientious professionals.

\section{PROBLEMS AND CHALLENGES OF MONITORING}

At first glance, the main problem with monitoring instrumentation (including hardware) lies in the great variety of artifacts and interferences, which commonly hamper generation of valuable information and occa- 


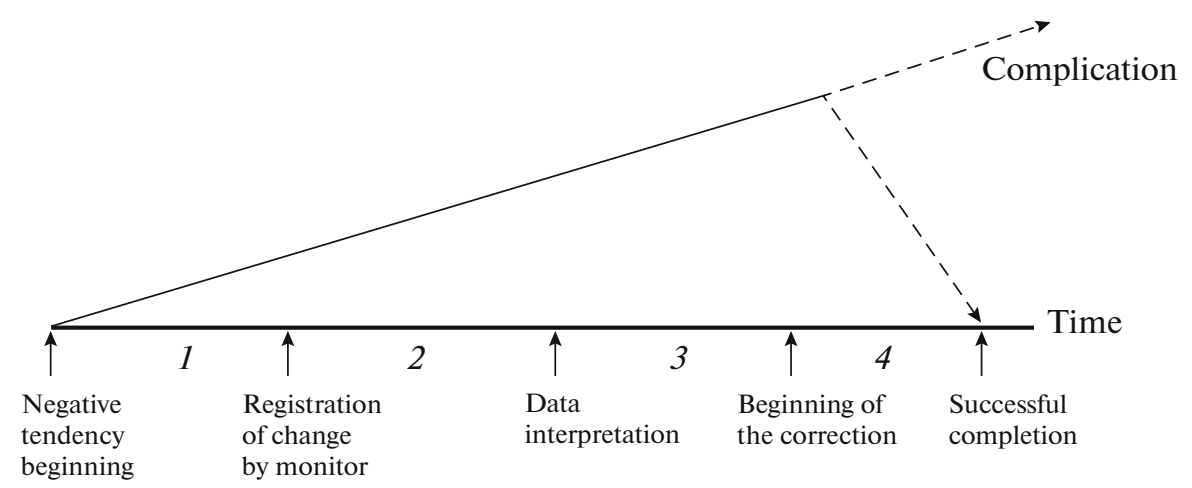

Fig. 2. Correction process of negative trend development: (1) period from the onset of the trend unfolding to the monitor recording the change in parameter, (2) period from detection by the operator of the change in parameter to understanding the cause, (3) period of decision-making on necessary actions, and (4) period from the beginning of correction to successfully solving the encountered problem [28].

sionally render monitoring impossible altogether. A textbook example of ECG artifacts from the operation of electrosurgical equipment displays a number of common patterns. Monitoring techniques that are primarily affected by artifacts include those that are intended to operate with physiological signals of low energy density (biopotentials, such as ECG, EEG, etc.), whereas energy-consuming "echo" signals prove to be protected to a higher degree (pulse oximetry, acceleromyography, impedance cardiography, etc.). Second, the quantity and nature of artifacts critically depend on the quality of the monitoring equipment, including incorporated hardware and software tools for signal filtering. Third, automatic interpretation of signal proves to be the most vulnerable in terms of errors; therefore, the universal rule of thumb is to turn off this option the moment that the signal becomes noise-contaminated.

The problem of artifacts is one of the main reasons that such a valuable (in terms of both scientific knowledge and practical application) technology of evoked potential (EP) has failed to occupy the place that it deserves in routine monitoring practice. Despite the fact that the evoked activity has an apparent advantage over a native EEG in terms of informational value, the need to isolate EP by the averaging technique under manifold repetitive stimulation and CNS response sometimes causes a significant delay in obtaining the result and "spread" (or rather diffusion or blurring) of the reference point in time. A low amplitude of the evoked response (sometimes by a factor of dozens (!) smaller than the amplitude of native EEG; in this particular case, the response signal is weaker than the spontaneous one) requires as many as several hundred repetitions for an interpretable EP to be obtained. The stimulus onset is a moment of support for such summation. As a result of this accumulation, the EP signal regularly linked to the stimulus increases much faster than does the noise of spontaneous rhythmic activity not associated with the stimulus [24]. A significant delay in obtaining the results, as well as specific recording conditions, and the need to use powerful signal filters limit wide application of this method in clinical practice. Among the multitude of technologies in the modern postoperative practice, only two appear to be underused: SSEP monitoring with spinal cord surgeries and carotid endarterectomy and middlelatency auditory evoked potential (MLAEP) for the measurement of hypnotic depth in general anesthesia (e.g., the AepEX plus monitor, Audiomex, United Kingdom) [25]. The latter is a unique technology that makes it possible to evaluate the depth of sedation in a patient under anesthesia by the agent causing socalled "dissociative anesthesia" with an atypical native EEG pattern (ketamine) [26].

Even so, it should be emphasized that it is not the artifacts and errors that present challenges in monitoring. Foreign colleagues that have been continuously dealing with the modern monitors over time are unanimous in their opinion that data interpretation is the main challenge that the monitor presents to personnel [27]. This was well-illustrated (Fig. 2) in the review by L.A. Eidelman et al. The Philosophy of Monitoring [28]. Note that the hardware problems are merely the first in a chain of the negative trend unfolding and its interruption. The remainder is made up by the effect of the human factor.

Difficulties in interpreting the monitoring data can arise as a result of a lack of understanding by a doctor or a nurse of physiological and/or physical principles of the monitor operation. Clearly, the first rule, and an essential one, in working with any type of monitor is an absolutely precise and understanding verbatim and literatim of what is displayed (at a primary physical or chemical level!) on it, rather than grasping the approximate rough idea. Based on teaching experiences, the problem is far from being solved. Thus, in the course of 18 years, not a single physician correctly responded to the questions "saturation of which blood specifically is shown by pulse oximeter" or "what does the 
abbreviation $\mathrm{SpO}_{2}$ stand for?" Moreover, in the modern foreign literature, it is possible to encounter such an expression as a "pulse oximeter's measure of arterial saturation $\left(\mathrm{SpO}_{2}\right)$ " [14]. However, without a valid answer to this question, there is no understanding of why the reading of the monitor will be $88 \%$ with the nitroglycerin infusion, whereas analysis of the arterial blood gasses displays $99 \%$ !

The so-called "monitor hypnosis" is an important special case of erroneous interpretation of data. Foreign colleagues teach young doctors to "never treat the monitor." At the same time, fixation on a single instrument with complete detachment from the context of events and other instruments is a common problem outside the area of medicine. According to the official report on the investigation of the crash of the Polish president's aircraft in Smolensk on April 10, 2010 [29], one of the main incorrect actions taken by the pilot on the glide path was concentrating on the navigator calling out the radio altimeter (RA-5) readings: the pilot did not alternate between the instruments and became disoriented with respect to the spatial position of the aircraft relative to the ground. The immediate cause of the collision between the SS Admiral Nakhimov and bulk carrier Petr Vasev in Tsemes Bay on August 31, 1986, was similar; specifically, the captain of the bulk carrier was navigating the vessel relying on radar and disregarding the visually observable heading directly into the ship [30].

The more advanced the monitors, the higher the probability of an error due to careless handling and failure to follow technical regulations and instructions, sometimes the most obvious ones. It does not matter that many of these guidelines do not directly concern specifically medical issues. Even the wrong last name or the weight and height of another patient stored in the monitor memory can lead to errors in interpreting the patient's state and, as a result, a wrong treatment strategy. There was a reason why, as early as in 1949, professional discipline took its rightful sixth place among the ten most pressing problems in U.S. healthcare [31]. The same applies to fields other than medicine. Thus, the disaster that was next after Chernobyl in severity, at the Three Mile Island nuclear plant (Pennsylvania, United States, March 1979) occurred, among other things, because the condensate pump failure indicator lights on the control panel were hidden behind a Wet Paint sign [32].

Information overload of operator is another problem known in ergonomics (engineering psychology) [33]. With screens of four or five monitors concentrated in an operating room, it is difficult for an anesthesiologist to both proceed with anesthesia and control all the parameters. We found have a simple solution, worked as a team of two or three people, which necessarily included a doctor that carried out responsibilities of a clinical physiologist. Aviation, which was faced by the similar problem way before the anesthesi- ology, managed to refine several means of solution. One of them is the so-called "director flight mode," in which the essential information to the pilot is presented in the form of a direct (explicit) instruction, such as "left-right" and "up-down," in other words, that does not require analysis. The aircraft is handled in this mode on a glide path by referring to the "arrows" of the flight director.

Another approach used in aviation is transition from a multitude of pointer instruments to so-called "integrated indicators" on LCD displays that present to the crew all the essential information in the form of a multicolor pictorial block diagram. Cockpits of aircrafts have changed beyond recognition during the past 20-30 years, which significantly improved the effectiveness of the crew operation and reduced the fatigue (Fig. 3). An analogous "ergonomic revolution" is expected to involve medical instrumentation in the near future, with sample units already being available. Thus, the Swiss manufacturer of ventilation solutions Hamilton Medical AG has implemented user-friendly display stimulator in the form of a block-schematic diagram to monitor the mechanism of a patient's respiration (it can be seen in operation in [34]).

Another option to reduce the information overload of the operator takes the form of clinical decision support (CDS) systems based on computer analysis of input data or fully automated response systems described in Subsection 3.5 below.

Another device that should not be overlooked and can be applied in the operating room is the so-called "head-mounted display." This valuable tool allows an anesthesiologist to control the monitored parameter without being distracted from events taking place in the operating room. It has been developed from being inapplicable due to inadequate resolution and short connecting cables between an HMD (HUD) and its computer in 1995 [35] to enthusiastic reviews from anesthesiologists in 2019: "the anesthesiologists who participated in the study expressed enthusiasm about monitoring patients with a head-worn display and wished to use and evaluate it further" [36]. It is possible that the next step forward for head-mounted displays will take the form of devices that use Google Glass as their prototype [37].

\section{PHYSIOLOGICAL AND PHYSICAL PARADOXES OF MEDICAL MONITORING}

General methodological problems exist in monitoring as a specific method for clinical observation on a real-time basis performed largely in unstable patients. These problems (which may be considered paradoxes of modern monitoring) are outlined below.

\subsection{Method Is Either Sought-for or Works}

It has long been known that any monitor works most consistently and produces the most accurate 
results with highest precision in ... a healthy person! In a sick person, i.e., when a doctor needs a result most, an enormous variety of interferences occur [1].

It has come recently into the mainstream in the world to "downgrade" monitoring parameters based on the fact that, in many specific clinical situations, they do fail to reflect a state of the physiological parameter or function that they were initially designed to characterize. Thus, the central venous pressure (CVP) and the pulmonary artery wedge pressure (PAWP) proved to be rather unreliable indicators of heart preload; normal arterial blood pressure (AP) is not always a guarantee of adequate tissue perfusion, whereas a severe systemic hypoperfusion can be accompanied by high cardiac output. Below, we present a table borrowed from a review by Bellomo and Uchino (2003) [38], the study of which requires a clear understanding that, notwithstanding the exact truth of everything outlined in the table, the orthodox transfer of the inferences into the routine practice can bring devastating consequences.

Known Clinical Facts with Respect to Accuracy of Monitoring of Circulation Parameters [38]

(1) CVP does not correlate with right ventricular diastolic pressure (L.D. Nelson, 1997).

(2) Correlation between PAWP and right or left ventricular end-diastolic volumes is unreliable (L.D. Nelson, 1997).

(3) CVP and PAWP fail to predict dynamics of cardiac output in response to fluid load by volume (L.N. Diebel, R.F. Wilson, M.G. Tagett, R.A. Kline, 1992; M.R. Pinsky, 2002; D.A. Reuter, T.W. Felbinger, C. Schmidt et al., 2002).

(4) It is impossible to evaluate cardiac output based on clinical signs (P.R. Eisenberg, A.S. Jaffe, D.P. Schuster, 1984).

(5) Normal values of mean AP do not indicate a sufficient level of cardiac output (P.R. Eisenberg, A.S. Jaffe, D.P. Schuster, 1984).

(6) Normal estimated values of oxygen transport do not indicate adequate organ perfusion (R. Schlichtig, D.J. Kramer, M.R. Pinsky, 1991).

(7) Normal oxygen content in mixed venous blood does not indicate adequate organ perfusion (J. Boldt, 2002).

(8) A change in oxygen consumption due to changes in its delivery does not necessarily indicate the occurrence of oxygen debt (R. Bellomo, M.R. Pinsky, 1996).

(9) PAWP does not correspond to the pressure in pulmonary capillaries in the time of wedging (M.R. Pinsky, 2003).

Not trusting all the navigational aids at once (although each of them separately has been known to produce errors under various circumstances) inevitably leads to shipwrecking. This allows only one conclusion to be drawn - that it is always desirable to use the maximum available information to avoid being at the mercy of the limitations of one monolithic method. On the other hand, a divergence of data produced for one parameter or procedure through different monitoring methods always offers a greater amount of information than coincidence if the causes for it are understood.

\subsection{Paradox of Time Point Spread}

This paradox of monitoring can be referred to as an "elusive meaning phenomenon." Any one-off measurement is known to contain a particular error regardless of it being systematic or accidental; the effect of errors can be reduced through statistical methods based on the collection and processing of a sizeable, to a greater or lesser degree, array of this type of discreet readings. Therefore, the error decreases as evaluation of the current state, which frequently changes at a dynamic rate, progressively spreads ("smeared") in the course of time. Thus, a physician is faced with a classical dilemma between knowing nearly everything about nothing or knowing nothing, but about everything.

\subsection{Unattainability of the Primary Targeted Parameter of the Monitored Function}

Unlike in experimental physiology, a quantitative assessment of many parameters is still unattainable in clinical practice, e.g., the main target circulation parameter, namely, tissue perfusion ( $\mathrm{mL} 100$ ((tissue $\left.\mathrm{g})^{-1} / \mathrm{min}\right)$ ). As a result, one evaluates the performance of a system and interferes with it (rather successfully) by using only indirect (implicit) information to control its effectiveness, e.g., "gross" blood flow or, in other words, blood flow per minute (cardiac output).

\subsection{Can Monitoring Influence Outcomes?}

As was mentioned earlier, that there be a salutary effect on the treatment outcome for patients is put forward as an important clinical requirement for monitoring [21, 22]. At the same time, there seems to be no monitor (which is itself a source of information) that can have an effect on the outcome without the mediation of medical personnel through their vigilance, decisions, and actions. The Japanese attack on Pearl Harbor on December 7, 1941, is a good example, showing that a fault-free operational position-radar station on its own does not improve AD efficiency. From this standpoint, it is no wonder that monitoring or not monitoring 20802 surgical patients with pulse oximetry did not affect the frequency of their postoperative complications and hospital deaths [39]. On the other hand, according to the British confidential questionnaire NCEPOD, the number of deaths from anesthesia dropped (for unknown reasons) from one case per 10 thousand anesthesia procedures in 1982 to one 


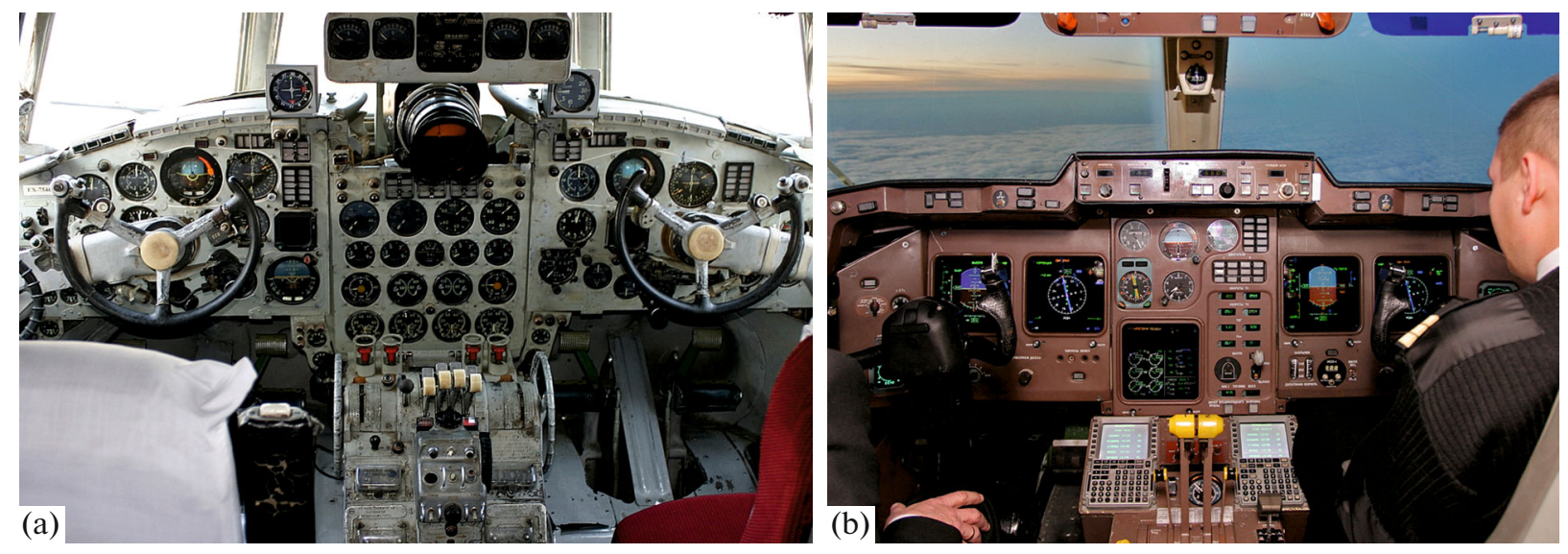

Fig. 3. Arrangement of instrument panels on turbopropeller passenger aircraft made by Ilyushin Design Bureau: (a) Il-18, 1957 (photo S. Bailleul, 2003), (b) Il-114, 1990 (photo F. Borisov, 2006) [1].

case per 200 thousand in 1987 [40], which, oddly, coincided with the commercial introduction of pulse oximeters in the United Kingdom...

The logic in reconciling the apparent contradictory natures of these facts can be better explained using as an example the dynamics of the opinion of the healthcare community on pulmonary artery catheterization with a balloon Swan-Ganz catheter over the period from 1970 to the 2000s [41]. At the time that the catheter was clinically introduced in the early 1970s, it was the only instrument available for clinical use that in real time and with good discreteness could provide extremely important data on cardiac efficiency and preload, systemic oxygen consumption, and, later, right ventricle function, intracardiac ECG, and continuous cardiac output monitoring, etc. Supporters of this method labored to accumulate for the first time an enormous array of numerical data on hemodynamics during anesthesia and intensive therapy procedures, with over a million of these highly invasive procedures having been performed in the United States by the mid-1990s [42]: as a matter of fact, almost every patient brought to American intensive care units was given a Swan-Ganz catheter. Concurrently, an increasing number of publications reported that the use of the catheter in the pulmonary artery in various categories of patients does not improve outcomes, but rather contributes to complications from catheterization itself and rising costs [43].

Ultimately, in September 1996, the Journal of the American Medical Association (JAMA) published a groundbreaking article by Alfred Connors et al. [44], which, based on the analysis of treatment outcomes in 5735 critically ill patients in five US teaching hospitals, demonstrated that the use of the Swan-Ganz catheter (right heart catheterization, RHC) not only increased both the length of stay in the ICU from 13 to 14.8 days and mean cost per hospital stay from 35700 to 49300 , but also decreased 30 -day survival by $24 \%$. This sensa- tional publication was accompanied by an editorial with the evocative title "Is It Time to Pull Out the Pulmonary Artery Catheter?" [45]. Although the design of the study raised a great deal of criticism (specifically, the study covered incurable patients), it did not take long for results to manifest. The country called for a national moratorium on the method [42], which immediately promoted an interest in noninvasive alternatives, namely, impedance metric and sonographic methods, while the pioneer of the SwanGanz catheter W.C. Shoemaker spoke out in favor of abandoning invasive monitoring [46].

In 1996-2006, multiple studies that involved thousands of patients demonstrated a lack of positive effect and/or increased risk of complications and fatalities associated with the pulmonary artery catheterization. Similar findings were obtained in patients exposed to myocardial revascularization [47], including openheart surgeries as a separate scenario [48]; in major elective surgery $[49,50]$; and in patients of general ICUs [51-53], as well as with decompensated heart failure [54], severe sepsis [55], and acute respiratory distress syndrome [56-58].

When analyzing these and other data, Leibowitz and Oropello (2007) [59] gave several explanations of the negative effects-primarily, the selection of the patient, many of which were "either too well or too sick" for to see an improvement in outcome using the monitoring data; second, there PAWP is limited as an indicator of preload; and, finally, a multitude of methodical errors in evaluation and interpretation of the monitoring parameters.

Amore measured response was offered by M.R. Pinsky and J.-L. Vincent in their article "Let Us Use the Pulmonary Artery Catheter Correctly and Only When We Need it" (2005) [60]. While declaring themselves against indiscriminate abandonment of the Swan-Ganz catheter, the authors noted a series of logical errors in the line of reasoning of objectors to 
the method proper. Risks associated with catheterization, except for rhythm disturbance, are primarily determined by central venous access, which no one was about to abandon, and pulmonary artery ruptures and nodulation specific to the Swan-Ganz catheter are very rare phenomena. Measurement of mixed venous oxygen saturation and pulmonary artery pressures is well developed, whereas PAWP measurement and interpretation errors require ongoing educational effort. The additional cost due to the catheter application of approximately $\$ 100-300$ is minimal relative to the cost of intensive care overall (the cost per bed-day on average in an intensive care unit in the United States cost was $\$ 12000$ in the early days of the 21 st century [61]). Last, but not least, no monitoring device can have an effect on patient-centered outcomes by itself. Data derived using a catheter can be considered only in the context of a clear treatment protocol, and only a comparison between the outcomes after following this protocol and a protocol that does not include catheterization can serve as an argument pro or contra it.

Therefore, a difficult question with an unascertainable answer can be resolved logically into two successive sequential questions, the responses to each of which are more obvious.

1. Does a specific monitor provide a physician with supplementary objective information about patient that cannot be received through other means?

2. Does this information (assuming that it has a grounded and uniform its effect on a therapeutic approach) have an impact on the patient outcome?

The current consensus on hemodynamic monitoring with shock (2014) does not support the routine use of the Swan-Ganz catheter in all patients in a state of shock, but, nevertheless, recognizes its role as a mediator in severe shock states and complex hemodynamic situations when shock is not responsive to therapy and with right ventricular dysfunction or acute respiratory distress syndrome [62].

\subsection{Why Has the Feedback Loop Still Not Been Closed?}

Another physicotechnical paradox lies in the fact that neither an advancement in hardware instruments of pickup, transmission, digital processing (filtration), and presentation (interpretation) of physiological signals nor the development of devices controlling the physiological functions or prosthesis design have not so far resulted in commercial implementation (introduction) of automatic control systems (ACSs) based on a closed loop of feedback response by physiological parameters. The primary constraint appears to be psychological; it is generally accepted that mode of mechanical ventilation or rate of administering a drug can be managed by a doctor exclusively, with an automated system being too unreliable. In the current national setting, this still entails criminal and litigious aspects [23], specifically, as to who will be responsible for the automated system failure. At the same time, it is hardly a surprise that the lives of 200-300 aircraft passengers lie in the safe "hands" of the autopilot, including the takeoff and landing stages.

It should be noted that the first wave of attempts to introduce ACSs based on physiological monitoring into anesthesiology and intensive care took place as early as in the 1950-1960ss. Thus, the first automatic ventilators, namely, the American Autoanestheton and Soviet ROA-2, automatically adjusted the respiratory rate to maintain an end tidal $\mathrm{PCO}_{2}$ preset by a doctor. It became clear later that these initial experiments proved largely to be an exercise in futility. A prominent panoramic picture of attempts to implement ACSs in anesthesiology is presented in a literature review of the V.M. Magilevets' doctoral thesis [63].

In addition, physicotechnical challenges exist in designing this type of ACS. Thus, finding the coefficients of a proportional-derivative-integral (PID) controller [64] requires knowledge of the natural oscillation frequency and time constant $\tau$ of the controlled object. Meanwhile, it is a challenge just to explain to a medical practitioner what "native frequency of pulmonary circulation" or " $\tau$ of MAP at administration of nitroglycerin bolus" mean.

At the same time, the development of a system with a closed feedback loop in which a medical practitioner only presets the targeted measurement and then this preset level is maintained is relevant and sought-after as never before by modern clinical practice. Systems such as the closed loop anesthesia delivery system (CLADS) possess obvious advantages, e.g., in anesthesiology, specifically for the reasons outlined below. These systems

(1) analyze the anesthesia parameters more frequently and thoroughly;

(2) reduce variation of anesthesia by minimizing the probability of serious errors and CIs [65];

(3) save anesthesiologists' time, thus allowing them to focus on important clinical tasks and make right decisions;

(4) appreciably reduce the probability of hypotension after induction of general anesthesia;

(5) provide overall for more stable hemodynamics during surgery; and

(6) improve activity when awake (BIS profile) $[66,67]$.

All of the above will contribute to easier and safer work on the part of anesthesiologists and critical care physicians, simplify documentation, and allow a physician to focus on a patient and work on solutions for more important clinical tasks, particularly in a complex or critical situation [68].

In February 2020, the leading international journal Anesthesiology published the results of a study con- 
ducted at the Brussels hospital Erasm in 2017-2019 [69]. Groups of 43 and 44 patients, for which control over the anesthesia, analgesia, fluid infusion, and lung ventilation was carried out by regular "manual" operations and three independent controllers (ACSs), respectively, were compared from the standpoint of anesthesia quality and cognitive impairment. Patients from the "automatic" group spent less time at BIS < 40 (overly deep anesthesia) and had a less end tidal hypocapnia and lower fluid balance compared to the manually managed group. In addition, they demonstrated a less pronounced postoperative cognitive impairment than did patients after traditionally managed anesthesia. Considering the prestige of the hospital conducting the work and the journal that published its findings, the future effect of this pilot trial on the mindset of the medical community cannot be overstated.

The design of this kind of system is clearly associated with objective difficulties.

First, there are challenges with an adequate interpretation of incoming physiological signal. The signal for the feedback system should be readily identifiable, dynamic, free from interferences and artefacts, and not easily affected by extraneous factors. In these terms, even the simple frequency transforms of a raw EEG have a great number of limitations for controlling the depth of anesthesia. While, for example, only the bispectral index (BIS), being the most acceptable alternative to physiological signal processing, can at the present moment serve this purpose with a certain degree of accuracy [66].

Second, the problem lies in the inadequate design of controllers, as well as the necessity for multivariable (multiparametric) analysis with a low probability of error and a high degree of system reliability. The solution to this problem appears to lie in a step-by-step abandonment of PID algorithms. Algorithms based on fuzzy logic, neural network, or reinforcement learning are a more reliable alternative to management of the processes that defy accurate mathematical description in the near future [70].

\subsection{Paradox of Analysis and Synthesis: Integrative Assessment of Body State}

Medical monitoring goes hand in hand with advances in medicine and primarily in an analytical way; from the first years of training onward, a physician is urged to analyze a patient's state based on "organs and systems." However, when gaining a more in-depth insight into separate functions (with at least 3000 parameters of states of organs and systems being known) [71], we increasingly overlook the functional state of the body (organism) (FSO), it being the whole entity. At the same time, practice often demands the integrative synthetic assessments of a state of a sick person located in a remote district, someone wounded or affected during triage, a pilot about to land on a carrier, athletes that are being selected for a competition, etc. Physicists and medical specialists, as well as physiologists and doctors in sports medicine, have more than once introduced various integrative indicators, thermometry scales, and functional tests qualifying for this role [72, 73]. Nevertheless, for various reasons, none of the latter have found widespread application in the everyday practice.

The work in this direction, however, is not only continuing, but receiving a great deal of attention. Along with analytical investigation, an "approach flow" has taken shape in studies that rises to increasingly higher systemic levels [74-76] and utilizes concepts such as those of a "functional system," "homeostasis," and "adaptation." Works by H. Selye, P.K. Anokhin, and R.M. Baevskii are recognized classics; no doubts exist with respect to the role of integrative systems, such as the endocrine and central and autonomic nervous system (ANS) and the importance of studying them [74, 75, 77].

The efforts applied to solve this paradox are discussed in Sections 4 and 5 of the present review.

\section{ANALYSIS OF HEART RATE VARIABILITY}

None of the parameters current known provide a clear picture of how critical a patient's state is. Analysis of heart rate variability (HRV) was among the first promising approaches to the solution of this type of tasks. The idea that the cardiovascular system is one of the most dynamic and, therefore, most sensitive and reliable indicators of all the processes taking place in the body, allowed for the selection of this key parameter characterizing the adaptation potential and homeostasis. R.M. Baevskii (b. 1928) is considered the founder of the method in the Soviet Union. For the benefit of space medicine in application to the mechanisms of heart rhythmogenesis, he used a supersystem approach, regarding the HRV as an integrative indicator of the functional body state. When the body functions under normal conditions, regulation is performed in a control mode, which is characterized by a large number of degrees of freedom of subordinate systems. In the processes of normal adaptation of the organism to the effects of stress factors, the leading role is played by the sympathetic chain link of autonomic nervous system (ANS), which integrates physiological systems, while bringing them to the required level of functional mobilization. This is accompanied by centralization of control with a decrease in the number of degrees of freedom and heart rate variability [78].

The development of this approach began with a temporal analysis of HRV, this being a form of statistical data analysis with elements of a probabilistic approach [79]. The calculated parameters (NN, AMo, Var, SDNN, RMSSD, etc.) and integrative indices 
(after Baevskii, vegetative balance, vegetative rhythm index, etc.) appropriately characterize the state of the cardiovascular system, presence of vago- or sympatotonia, and degree of strain of extracardiac rate regulation [79-84]. More information can be derived when processing HRV data using methods that evaluate the contribution of particular periodic components in the rate (rhythm) dynamics. Mathematical transforms, such as the fast Fourier transform, allow for representation of a cardiointervalgram in the form of regular sinusoid interferences of different frequencies and amplitudes. This is followed by the calculation of spectral power of oscillations; the areas under the curves of the particular frequency (wavelength) ranges are then determined. The ratio between the powers of the spectrum components characterizes the relative contributions of the sympathetic and parasympathetic pathways to the rhythm regulation [78-84].

One variety of spectral analysis is the wavelet transform, which also reveals information discrete (imperceptible) in the frequency-temporal representation of the signal. Here, the role of sinusoids into which the signal is decomposed is played by short oscillations (wavelets) [85], with the nonstationary signal being analyzed through decomposition based on functions obtained from a prototype by way of compression, stretching, and shifts. The prototype function is named the "analyzing (mother) wavelet," selection of which is determined on the basis of the type of information needed to be derived from the signal [86].

The inhomogeneity of the sinus rhythm formation process can be assessed by correlation analysis techniques; that is, the more pronounced the various influences on the process, the weaker the relationship between the succeeding and preceding values of the examined dynamic series. The autocorrelation function reflects the dynamics of correlation coefficients obtained with a consecutive shift of the analyzed dynamic series by one and the same number relative to the initial series [75, 78]. The less homogenous a series is (which is an indication of independent control loop instability), the more appreciable the decrease in the correlation coefficient is already after the first shift. Nonstationary rhythms, e.g., with atrial fibrillation, are described by a correlational rhythmogram or scattergram of $\mathrm{R}-\mathrm{R}$ intervals on a plane in a rectangular grid: the value of $\mathrm{R}-\mathrm{R}_{n}$ is noted by the abscissa, and $\mathrm{R}-\mathrm{R}_{n+1}$ is plotted on the ordinate. Clouds of points (Poincaré or Lorenz maps) concentrated on the bisector of the coordinate angle indicates effective control by the primary pacemaker over the rhythm; modeless scattergrams with scattered clouds reflect a lack of control by the SA node of secondary pacers $[82,83]$.

The further development of HRV study methods is creating an opportunity for investigating the rhythm nonlinear dynamics [87] as a component of a complex system with a large number of relationships and diverse effects characterized by dynamical chaos (self- sustained by stochastic oscillations) and fractality (self-organizing symmetry of self-similarity). Symbiosis of deterministic and chaotic components of the fractal structure is displayed during the analysis of many rhythms reflecting the physiological parameters of energy exchange and self-regulation, such as the electrical potentials of the heart, brain, and gastrointestinal tract; the breathing pattern; limb tremor; oscillation of potentials on the fluid-tissue interface; etc. [88]. Other signs of chaotic oscillations of physiological signals include a continuous power spectrum with negative frequency dependence, an autocorrelation function rapidly dropping with time, and a positive Lyapunov characteristic exponent [89].

The stochastic irregularity of such signals in "value-speed of its change" coordinates is manifested in the form of an attracting set of phase trajectories (the so-called "strange attractor" [90]) exhibiting a fractal dimension, which quantitatively reflects the non-Euclidean dependence between speeds of growth of fractal elements and the scales of the intervals on which they are considered [91]. Qualitative assessment in the phase space of this attracting set organized by chaotic behavior of a complex dynamic system of a deterministic chaos character is performed using the attractor's visual picture, which determines the cause of the irregular behavior of nonlinear systems through an exponential fast divergence of initially close trajectories in a bounded region of phase space [80]. The reestablished from $\mathrm{R}-\mathrm{R}$-intervalogram attractor in an $\mathrm{N}$-dimensional phase space will reflect FSO. It is possible to identify the contour of adaptation and assess its strain based on the dynamics of the attractor dimension with different stress tests [80, 92].

Analysis of nonlinear rhythm dynamics demonstrated that a (eutonic) state of balanced interaction between all rhythm regulation chain links is characterized by a phase portrait with a dominance of ellipselike cycles of the rhythm wave structure; that is, first, the heart rate gradually increases and, then, decreases. On the phase portrait, the strange attractor is represented by a "ball of yarn," where the dimension of the system is determined by multiple factors that contribute to FSO (Fig. 4a). The disturbance of harmony in the interaction between vegetative and humoral rhythm regulations alters the geometrical structure of the phase portrait: the dimension of the attractor declines (Fig. 4b) [80, 93].

With the application of nonlinear analysis, HRV studies caught a second wind. The phase portrait of the sinus rhythm, which reflects the nonlinear dynamics of a totality of external conditions and internal heart regulation, is embodied in the spatial image of an individual virtual web [94]. The form, span, and spatial orientation of the phase portrait synthesize in themselves both a temporal series and spatial volume of rhythm variability. This is possibly what was meant by Baevskii when he described the HRV characteristic 
(a)

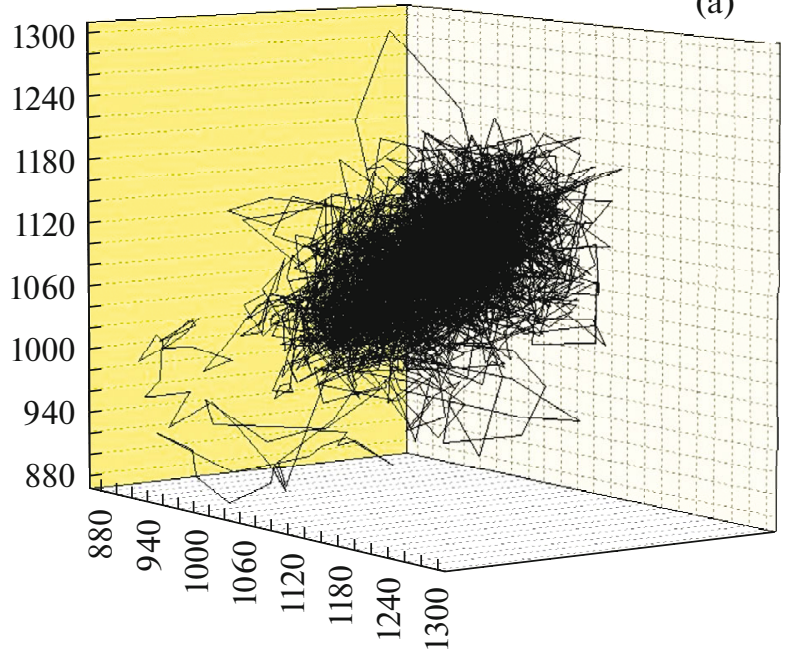

(b)

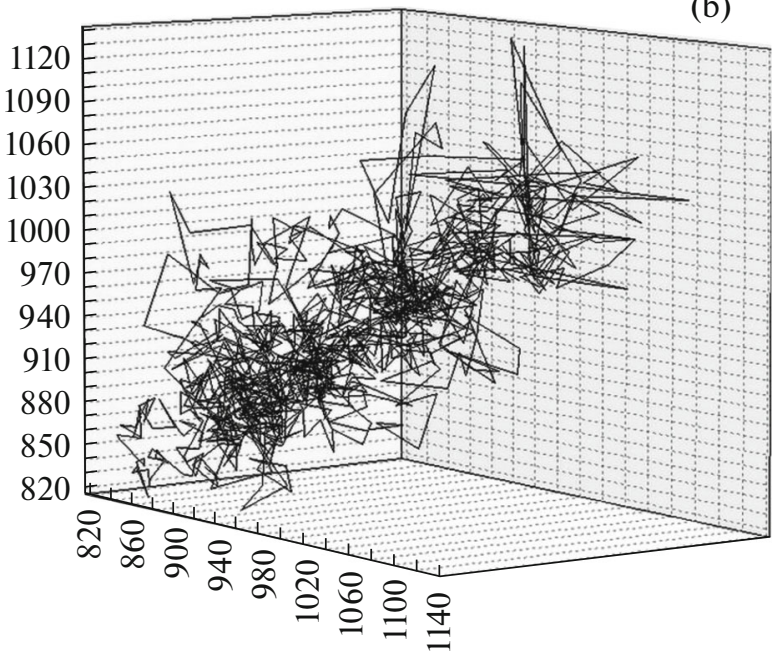

Fig. 4. Phase portrait of heart rate: (a) healthy person, (b) with abnormality [93].

from the general biological perspective as a regular manifestation of the essence of the key concept of "life" [95].

\section{APPLICATION OF PHYSICAL AND INFORMATIONAL METHODS FOR INTEGRATIVE FSO ASSESSMENT}

The most promising ideas in the study of the state of an organism as the whole entity originate, as one would expect, from the field of physics. With the development of quantum mechanics and thermodynamics, the focus of research shifted toward investigation of stochastic and nonlinear processes described by probabilistic-statistical models. Attempts to describe idealized special cases of the behavior of a complex system by reference to an unambiguous single cause receded into the historical distance together with the deterministic epoch typical of the natural history of the 17 th -19 th centuries [96]. The majority of scientific fields reconstructed their fundamental theories based on the new paradigm [97]; notwithstanding, medical science continued to be dominated by "empirical" (or, better said, "archaic") ideas on the deterministic nature of cause-effect relations in an extremely complex open system, such as a live organism. Despite the declaration that a personalized approach is taken, the modern idea of randomized clinical trials and clinical recommendations constructed on their results almost entirely disregards both the individual characteristics of a patient and interrelationship of damage between different systems of the body. This was objectively provoked (pushed forward) by the epoch-making discovery of the etiology of infectious and parasitic diseases; that is, each of them is caused by its own specific causative agent; therefore, that there would be cause-effect relations was, in fact, predetermined. Later came the under- standing that, while one person who comes in contact with a disease will contract it, another will not; the same virus causes measles in one patient, encephalitis in another, and shingles in the third ... However, nevertheless, in the identification of a causative agent and etiotropic treatment, medicine hold true to its notion, which this explains the efforts (sometimes successful ones) to find causative agents of tumors, stomach ulcers, and even fatigue.

Niels Bohr (1885-1962) approached the problem from the standpoint of a complementarity principle, assuming, similarly to the principle of uncertainty in quantum mechanics, the study of the live objects at a molecular level and as entire systems to be complimentary to each other, in other words, antithetic. Bauer's Theoretical Biology put forward the concept of a special physical state of "live matter" [98]. These ideas were abandoned with the advancement of molecular biology, which led to an atomistic interpretation of heredity and variation [99], on the one hand, and the development of physical theory of biosystems based on ideas of synergetics [100], taking into account the formation and self-organization of ordered dynamic structures in open systems that are far from thermodynamic equilibrium, on the other. In the middle of the 20th century, Erwin Schrödinger (1887-1961), in his book What is Life? The Physical Aspect of the Living Cell, introduced an interpretation of the organism as an open system, which exchanges matter and energy with the external environment and the nonequilibrium state of which is maintained through outflow of entropy to the environment [101].

Understanding this equilibrium creates makes donozological diagnostics based on evaluation of discordance of the results of direct and indirect calorimetry possible. The logic is constructed on the basis of the second law of thermodynamics, which establishes 
the direction of self-organizing energy transformation processes, as well as the accompanying change in entropy as a measure of its dissipation and criterion of thermodynamic evolution of the organism and the theorem of I.R. Prigozhin on the minimal production of entropy for the stationary states [102, 103]: the condition for a stationary state is equality between products of entropy produced by the body and the energy flow beyond its boundaries [102]. Contrary to chronic adaptation, which features largely a structural morphological character, acute adaptation is energydependent and its intensity can be determined on the basis of the energy balance, as well as by accompanying changes of entropy as a measure of its dissipation and criteria for the thermodynamic evolution of the organism. This makes it possible to diagnose FSO changes at an early stage of energy exchange restructuring and to control homeostasis [104]. Any irreversible process is accompanied by an increase in heat dissipation production, and, therefore, production of entropy will be accompanied by divergence of the readings of the first calorimeter of the estimated data from the indirect calorimetry in favor of the first. The opposite is equally true: everything related to the enhancement of synthesis processes and increased structuredness of live matter leads to a decline in entropy production and predominance of the estimated value [75]. Regretfully, bulky calorimeters for the entire body preclude realization of this monitoring method not only in the operating room, but also in an intensive care unit.

An alternative approach to integrative FSO assessment and prediction of threats to the organism vital functions involves the entropy estimation of the intensity of regulatory effects based on information richness of the homeostasis controlling processes reflected in variability of its physiological rhythms. This approach relies on modern ideas of synergetic understanding of self-organization of the interrelated functioning of organs of the live organism as a nonequilibrium open system and probabilistic-statistical interpretation of the notion of entropy proposed by Ludwig Bolzman (1877) [105]. Entropy, as a measure of disorder, directly depends on thermodynamic probability of a system's state. The larger the number of microstates through which a macrostate can be realized (i.e., the lower the system order level), the higher the probability of such a state, i.e., entropy. Later, from the standpoint of information theory, K. Shannon and N. Winner extrapolated the concept of entropy beyond the boundaries of thermodynamic systems [106], while having demonstrated an interrelation between Bolzman's ideas of information entropy (or the amount of information about system) and thermodynamic entropy. Such identification makes it possible, using the rather justified analogy of regularities known in thermodynamic entropy, to assess (based on information entropy) a state of the organisms in terms of order or disorder of functioning of its components
[107, 108]. The evaluation of information entropy is technically possible through other, simpler ways; the input data can be represented by discreet temporal sequence of biomedical signals of any nature, such as electrocardiograms, electroencephalograms, photoplethysmograms, breathing rhythms or values of stroke output, etc., the histograms of which reflects the frequency probability of the current distribution of FSO characteristics [109].

The idea was externalized, in among other ways, in the method for monitoring and prediction of general FSO stability based on the fractal analysis of generation of information entropy of physiological rhythms $[75,110]$. As mentioned earlier, the assessment of a state of an extremely complex dynamic system exposed to a great variety of effects (impacts) requires application of nonlinear research techniques. It is necessary to construct and analyze the phase portrait of the dynamic system to be able to observe its evolution over time. Combining the theoretical prerequisites of the nonlinear methods of HRV analysis and estimates of the physical entropy production in the processes of energy and matter exchange of the organism based on the information richness of regulatory effects on homeostasis allows for FSO monitoring based on a phase portrait of an entropy attractor. For quantitative assessment of its characteristics, the authors used probabilistic (fractal) dimensions, the general basis of which is formed by the Rényi dimension [111], in special cases transforming into the known expressions of Kolmogorov-Sinai-Hausdorf-Shannon. Thereafter, taking into account the known ambiguity of the concepts of "norm" and "abnormality," as well as the priority of preemptive assessment of the progression of critical states, a detection and predictive estimate of the threats' strain is carried out on the basis of a dynamic trend in the fractal dimension of an attractor of entropy, the density of generation of which in a system of interrelated organs reflects in an integrative manner the evolution of a state of the organism overall. The functionality of the patented tool of monitoring the human FSO on a real-time basis [112] was proved in the trials, relying on ECG recordings of both clinical and high resolution with a high digitizing rate available for modern cardiographs and Holter monitors. There exists a software product for mathematical processing that has been tested on existing models of dynamical chaos systems (Ressler and Lorenz) and nonlinear mapping (Hénon, Ikeda, and Lozi) approbated in preclinical and clinical trials, including with the involvement of databases of the PhysioNet European medical server [113]. A source of diagnostic data in ECG variations is presented by "attractor" mappings of (concurrently) the amount and speed of change in information entropy generated with it, reconstruction of which in time series of standard measurement is performed using the method of the delay including Taken's theorem [114]. 

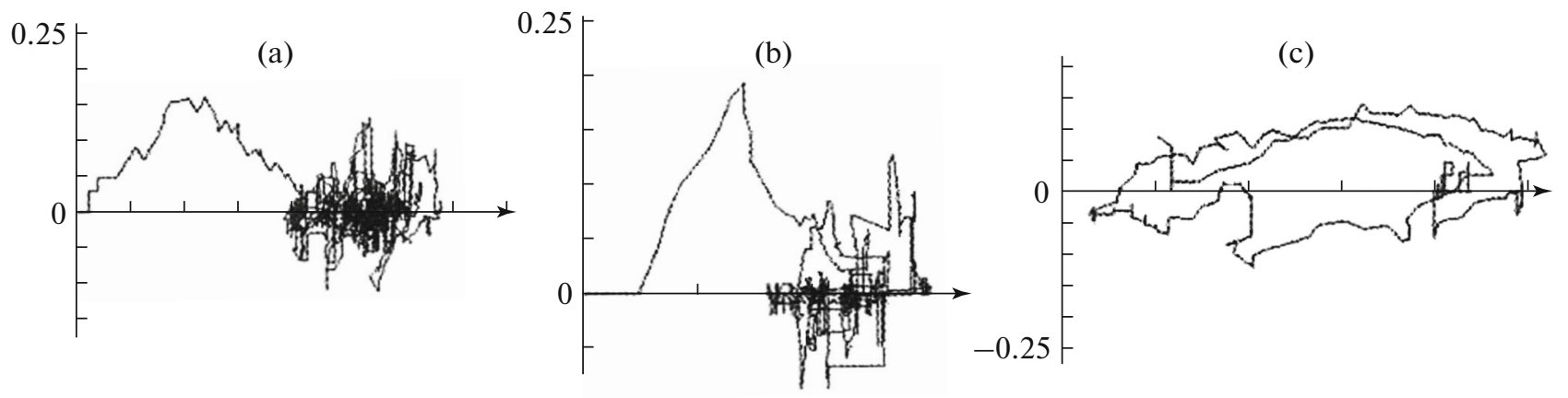

Fig. 5. "Entropy state": (a) boy 14 yr.o, (b) woman 79 yr.o., (c) man 57 yr.o. with serious disturbance of the blood flow in the brain $3 \mathrm{~min}$ before death [75].
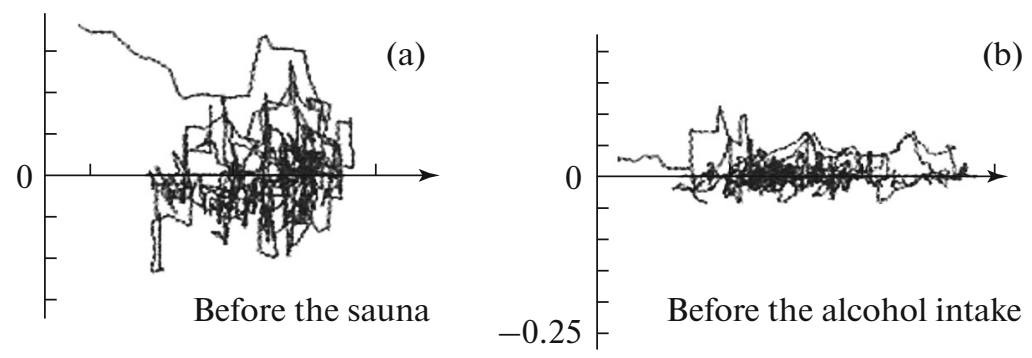

(b)
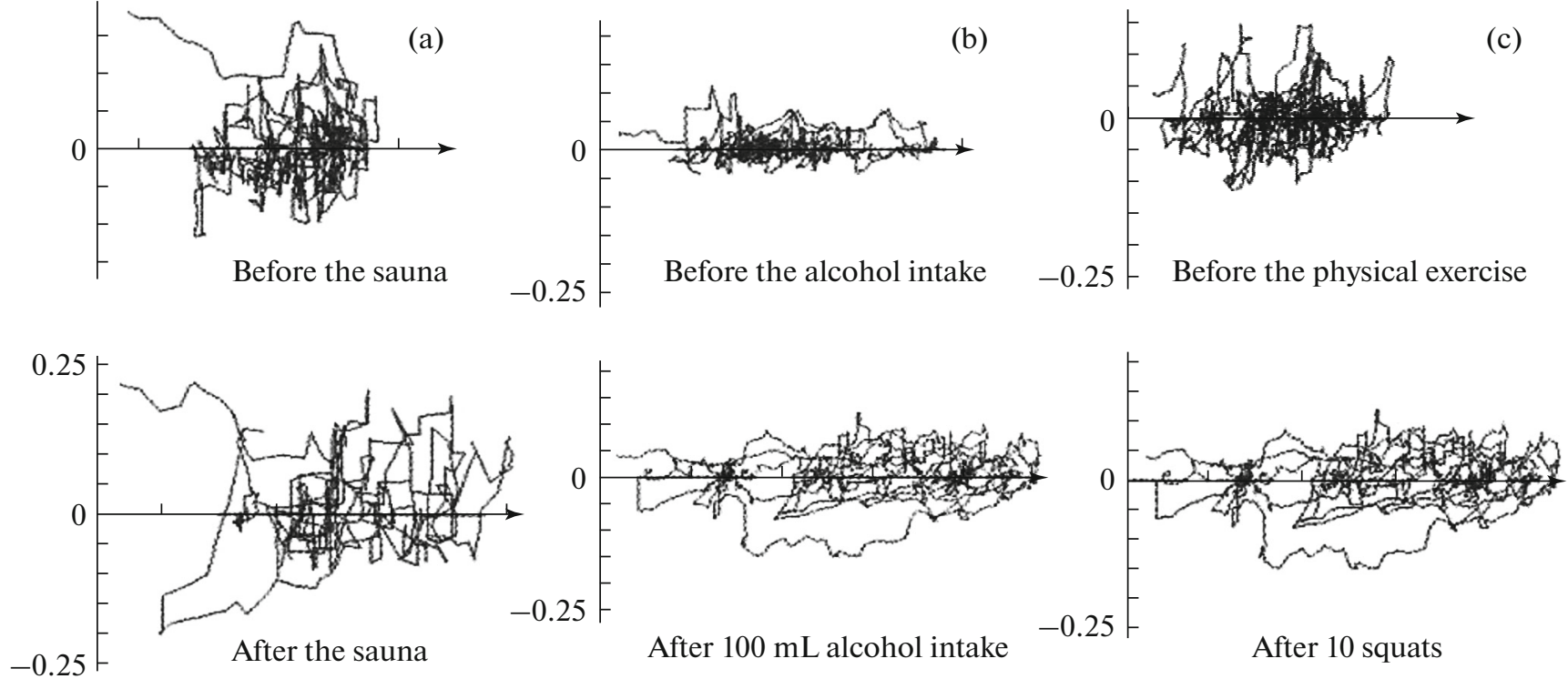

Fig. 6. "Entropy state" of healthy persons: (a) changes after sauna, (b) effect of alcohol intake, and (c) effect of physical exercise [75].

The present study has shown that there are differences between persons of various genders and ages lying in the visually distinguished "density" of phase trajectories in attractor of the ECG information entropy, ranging from a "tight yarn ball" in a healthy young person (Fig. 5a) to the "ball loosening" with sickness and age (Fig. 5b), as well as with exposure to heat (Fig. 6a), alcohol (Fig. 6b), and physical loads (Fig. 6c), all the way to deterioration to the "unraveled loops" in a dying patient (Fig. 5c). The analysis of trends of correlation dimension of entropy attractors allows the following inferences to be drawn [75, 115].

1. A healthy organism is characterized by oscillation of fractional correlational dimension within the range of $1-3$ with a decrease in the nighttime.

2. Short episodes are possible when the correlation dimension declines to within the range from 0 to 1 at night in both healthy and sick persons, which appear to be related to changes in the heart rate during sleeping.

3. Life-threatening changes in correlation dimension, requiring intensive observation and treatment, are reflected by, first, its consistent approach to the whole number value and its continuous persistence (long-term retention) and, second, sharp and prolonged decline of correlation dimension to the interval of $0-1$.

Importantly, "synthetic" FSO monitoring is intended not to replace, but supplement, conventional analytical types of monitoring, which serve to identify the damaged chain link. The tasks solved by both types of monitoring differ, but they are equally important.

\section{CONCLUSIONS}

Medical monitoring is a continuous observation over a period of time of a particular physiological 
parameter, process, or function in a real time, which supplies medical personnel with information that, providing its correct and uniform interpretation, can assure making timely strategic decisions and taking actions that can positively influence treatment outcomes. The most challenging problems of monitoring that can impact its clinical effectiveness include adequacy of interpretation of data received by the medical personnel; interferences and artefacts, which increase as a patient's state deteriorates and create tension between the accuracy and the temporal focus sharpening of readings; technological discipline while operating a monitor; and information overload of the operator. Optimal medical monitoring implies a balanced combination of the objects, methods, and technologies, and an excessive fixation on any single object, method, or technology inevitably leads to a distorted perception of situation and often to direct damage to a patient. Two complex tasks demand undivided attention of physicians and engineers, that is, designing automated physical functions control systems on the basis of a closed feedback loop and monitoring of the integrative assessment of a physiological state of the human body.

\section{CONFLICT OF INTEREST}

The authors declare that they have no conflicts of interest.

\section{REFERENCES}

1. K. M. Lebedinskii, "Monitoring As a Method in Anesthesiology," in Blood Circulation and Anesthesia, 2nd ed. (Chelovek, St. Petersburg, 2015), pp. 104-127 [in Russian].

2. Merriam-Webster's Collegiate Dictionary (MerriamWebster, Springfield, 1993).

3. New Words and Meanings. Dictionary-Reference, Ed. by N. Z. Kotelova and Yu. S. Sorokin (Sov. Entsiklopediya, Moscow, 1973) [in Russian].

4. The American Heritage Dictionary of the English Language, Ed. by W. Morris (American Heritage Publ., New York, 1969).

5. I. Kh. Dvoretskii, Latin-Russian Dictionary, 2nd ed. (Russkii Yazyk, Moscow, 1976) [in Russian].

6. J. H. Eichhorn, J. B. Cooper, D. J. Cullen, W. R. Maier, J. H. Philip, and R.G. Seeman, J. Am. Med. Assoc. 256 (8), 1017 (1986).

7. Siegenthalers Differenzialdiagnose Innerer Krankheiten-vom Symptom zur Diagnose, Hrsg von E. Battegay, 20 Aufl. (Georg Thieme, Stuttgart, 2013).

8. J. Ehrenwerth, J. B. Eisenkraft, and J. M. Berry, Anesthesia Equipment: Principles and Applications, 2 nd ed. (Saunders, 2013), pp. 257-272.

9. J. W. Severinghaus and P. B. Astrup, J. Clin. Monit. Comp. 2 (4), 270 (1986).

https://doi.org/10.1007/BF02851177
10. E. M. Kreps, Oximetry. Technique, Application in Physiology and Medicine (Medgiz, Leningrad, 1959) [in Russian].

11. R. C. Steven, H. M. Slater, and A. L. Johnson, Anesthesiology 12, 548 (1951).

12. G. L. Kotomina, I. A. Domanskaya, and K. M. Lebedinskii, Series "Our Scientists": Vladimir L'vovich Vanevskii (St. Petersburg Med. Acad. Postgraduate Studies, St. Petersburg, 2006) [in Russian].

13. S. Barker, J. Curry, D. Redford, and S. Morgan, Anesthesiology 105, 892 (2006).

14. A. Jurban, Crit. Care 19, 272 (2015). https://doi.org/10.1186/s13054-015-0984-8

15. K. M. Lebedinskii, V. A. Mazurok, and K. M. Matus, Biomed. Eng. 44 (4), 142 (2010). https://doi.org/10.1007/s10527-010-9173-x

16. J. B. Cooper, R. S. Newbower, C. D. Long, and B. McPeek, Anesthesiology 49, 399 (1978).

17. R. K. Webb, M. Currie, C. A. Morgan, J. A. Willianson, P. Mackay, W. J. Russell, and W. B. Runciman, Anaesth. Intensive Care 21 (5), 520 (1993).

18. A. K. Jha, G. J. Kuperman, J. M. Teich, L. Leape, B. Shea, E. Rittenberg, E. Burdick, D. L. Seger, M. Vander Vliet, and D. W. Bates, J. Am. Med. Inform. Assoc. 5 (3), 305 (1998). https://doi.org/10.1136/jamia.1998.0050305

19. E. B. Lee and L. Markus, Foundations of Optimal Control Theory (Wiley, New York, 1967).

20. P. Ya. Popovskikh and A. V. Kukushkin, Military Intelligence Training (Voenizdat, Moscow, 1991) [in Russian].

21. J. B. Hall, in Functional Hemodynamic Monitoring, Ed. by M. R. Pinsky and D. Payen (Springer, 2005), pp. $233-240$.

22. G. Satkurunath, A. Rhodes, and M. Cecconi, in Patient Safety and Quality of Care in Intensive Care Medicine (ESICM), Ed. by J.-D. Chiche, R. Moreno, C. Putensen, and A. Rhodes (Medizinisch Wissenschaftliche, Berlin, 2009), pp. 433-440.

23. Investigation of Crimes Committed by Medical Professionals Due to Negligence (Iatrogenic Crimes) (Yuniti-Dana, Moscow, 2016) [in Russian].

24. V. V. Gnezditskii, Evoked Brain Potentials in Clinical Practice (MEDpress-Inform, Moscow, 2003) [in Russian].

25. J. Tsurukiri, K. Nagata, A. Hoshiai, T. Oomura, H. Jimbo, and Y. Ikeda, Scand. J. Trauma, Resusc. Emerg. Med. 23, 80 (2015). https://doi.org/10.1186/s13049-015-0161-8

26. E. Kochs and P. Bischoff, Der Anaesth. 43 (Suppl. 2), S8 (1994).

27. P. E. Marik, Handbook of Evidence-Based Critical Care (Springer, 2001).

28. L. A. Eidelman, R. Pizov, and C. L. Sprung, Curr. Opin. Crit. Care 2 (3), 183 (1996).

29. Interstate Aviation Committee, Final Accident Investigation Report. https://mak-iac.org/upload/iblock/807/finalreport_rus.pdf

30. D. T. Chapkis, Death "Admiral Nakhimov" (Prof-Press, Rostov-on-Don, 1995) [in Russian]. 
31. R. M. Hewitt, The Physician-Writer's Book (Sounders, London, 1957).

32. J. G. Collier and G. F. Hewitt, Introduction to Nuclear Power (Hemisphere, New York, 1987).

33. M. A. Kotik, The Course of Engineering Psychology (Valgus, Tallin, 1978) [in Russian].

34. https://www.hamil-ton-medical.com/ru_RU/ELearning-and-Education/College.html

35. F. E. Block, Jr., D. O. Yablok, and J. S. McDonald, Int. J. Clin. Monit. Comput. 12 (1), 21 (1995).

36. P. D. Schlosser, T. Grundgeiger, P. M. Sanderson, and O. Happel, J. Clin. Monit. Comput. 33 (6), 1119 (2019). https://doi.org/10.1007/s10877-019-00265-4

37. T. F. Drake-Brockman, A. Datta, and B. S. von Ungern-Sternberg, Pediatr. Anesth. 26 (9), 539 (2016). https://doi.org/10.1111/pan.12879

38. R. Bellomo and S. Uchino, Curr. Opin. Crit. Care 9, 225 (2003).

39. J. T. Moller, N. W. Johannessen, K. Espersen, O. Ravlo, B. D. Pedersen, P. F. Jensen, N. M. Rasmussen, L. S. Rasmussen, T. Pedersen, J. B. Cooper, et al., Anesthesiology 78 (3), 445 (1993). https://doi.org/10.1097/00000542-199303000-00007

40. Anaesthesia for the High Risk Patients, Ed. by I. McConachie (Greenwich Medical Media, London, 2002).

41. K. M. Lebedinskii and I. S. Kurapeev, "Catheterization of the Pulmonary Artery," in Blood Circulation and Anesthesia, 2nd ed. (Chelovek, St. Petersburg, 2015), pp. 294-339 [in Russian].

42. G. Cowley and M. Hager, Newsweek 30, 71 (1996).

43. J. H. Gore, R. J. Goldberg, D. H. Spodnick, J. S. Alpert, and J. E. Dalen, Chest 92, 721 (1987).

44. A. F. Connors, Jr., T. Speroff, N. V. Dawson, et al., J. Am. Med. Assoc. 276, 889 (1996).

45. J. E. Dalen and R. C. Bone, J. Am. Med. Assoc. 276, 916 (1996).

46. W. C. Shoemaker, Proc. 6th All-Russian Meeting of Anesthesiologists and Resuscitators, Moscow, Russia, 1998, pp. 44-45.

47. S. D. Ramsey, S. Saint, S. D. Sullivan, et al., J. Cardiothor. Vasc. Anesth. 14, 113 (2000).

48. F. G. Resano, E. Kapetanakis, P. C. Hill, et al., J. Cardiothor. Vasc. Anesth. 20, 300 (2006).

49. J. D. Sandham, R. D. Hull, R. E. Brant, et al., N. Engl. J. Med. 348, 5 (2003).

50. C. A. Polanczyk, L. E. Rohde, E. Goldman, et al., J. Am. Med. Assoc. 286, 309 (2001).

51. S. Harvey, D. A. Harrison, M. Singer, et al., Lancet 366, 472 (2005).

52. A. Rhodes, R. J. Cusack, P. J. Newman, et al., Intensive Care Med. 28, 256 (2002).

53. Y. Sakr, J.-L. Vincent, K. Reinhart, et al., Chest 128, 3098 (2005).

54. C. Binanay, R. M. Califf, V. Hasselblad, et al., J. Am. Med. Assoc. 294, 1625 (2005).

55. D. T. Yu, R. Platt, P. N. Lanken, et al., Crit. Care Med. 31, 2734 (2003).

56. C. Richard, J. Warszawski, N. Anguel, et al., J. Am. Med. Assoc. 290, 2713 (2003).
57. P. Wheeler, G. R. Bernard, B. T. Thompson, D. Schoenfeld, H. P. Wiedemann, B. deBoisblanc, A. F. Connors, Jr., R. D. Hite, and A. L. Harabin, N. Engl. J. Med. 354, 2213 (2006). https://doi.org/10.1056/NEJMoa061895

58. H. P. Wiedemann, A. P. Wheeler, G. R. Bernard, B. T. Thompson, D. Hayden, B. deBoisblanc, A. F. Connors, Jr., R. D. Hite, and A. L. Harabin, N. Engl. J. Med. 354, 2201 (2006).

https://doi.org/10.1056/NEJMoa062200

59. A. B. Leibowitz and J. M. Oropello, Semin. Cardiothor. Vasc. Anesth. 11, 162 (2007).

60. M. R. Pinsky and J.-L. Vincent, Crit. Care Med. 33, 1119 (2005).

61. D. C. Angus, W. T. Linde-Zwirble, J. Lidicker, et al., Crit. Care Med. 29, 1303 (2001).

62. M. Cecconi, D. De Backer, M. Antonelli, et al., Intensive Care Med. 40, 1795 (2014). https://doi.org/10.1007/s00134-014-3525-z

63. V. M. Magilevets, Doctoral Dissertation in Medical Sciences (Inst. Transplantal. Isskust. Organov Roszdrava, Moscow, 2006).

64. A. N. Gusev, System of Automatic Control of the Aircraft (Samara Gos. Aerospace Univ., Samara, 2004) [in Russian].

65. P. S. Myles, K. Leslie, J. McNeil, et al., Lancet 363, 1757 (2004).

66. Z. Hajat, N. Ahmad, and J. Andrzejowsky, Anaesthesia 72 (Suppl. 1), 38 (2017). https://doi.org/10.1111/anae.13739

67. M. Neckebroek, C. M. Ionescu, K. van Amsterdam, et al., J. Clin. Monit. Comput. 33 (4), 675 (2018). https://doi.org/10.1007/s10877-018-0208-2

68. A. M. Atchabahian and T. Hemmerling, Anesth. Pain Med. 4 (1), 16468 (2014).

https://doi.org/10.5812/aapm.16468

69. A. Joosten, J. Rinehart, A. Bardaji, et al., Anesthesiology 132, 253 (2020). https://doi.org/10.1097/ALN.0000000000003014

70. G. A. Dumont and J. M. Ansermino, Anesth. Analg. 117 (5), 1130 (2013). https://doi.org/10.1213/ANE.0b013e318297368

71. Human. Medical and Biological Data (Meditsina, Moscow, 1977) [in Russian].

72. V. B. Voinov, N. V. Voronova, and V. V. Zolotukhin, Methods for Assessing the State of Human Oxygen Supply Systems (UNII Valeolog. Rostov Gos. Univ., Rostovon-Don, 2002) [in Russian].

73. E. K.Tsybul'kin and L.D. Meshalkin, Comp. Technol. Med. 2, 49 (1997).

74. G. M. Aldonin, N. P. Bolotova, A. N. Tacheev, and S. P. Zhelud'ko, Proc. Sci.-Tech. Conf. "Modern Problems of Radio Electronics" (Radio i Svyaz, Moscow, 2010), p. 48 [in Russian].

75. S. P. Nosyrev and A. N. Kovalenko, Bases of Anesthesiology and Resuscitation (Klyuch-S, Moscow, 2014) [in Russian].

76. C. Chen, Y. Jin, I. L. Lo, et al., Int. J. Biol. Sci. 13 (10), 1320 (2017).

https://doi.org/10.7150/ijbs.19462 
77. S. B. Mulkey, S. Kota, C. B. Swisher, et al., Early Hum. Dev. 123, 11 (2018). https://doi.org/10.1016/j.earlhumdev.2018.07.003

78. R. M. Baevskii, O. I. Kirillov, and S. Z. Kletskin, The Mathematical Analysis of Changes of a Cardiac Rhythm at Stress (Nauka, Moscow, 1984) [in Russian].

79. V. V. Parin, R. M. Baevskii, Yu. N. Volkov, and O. G. Gazenko, Space Cardiology (Meditsina, Leningrad, 1967) [in Russian].

80. Guidelines for Analyzing Cardiac Rhythm Variability in Athletes in Endurance Sports Using Mathematical Methods, http://csp-athletics.ru/metodicheskie-rekomendatsii-po-kontro-lyu-sostoyaniya.html

81. Task Force of the European Society of Cardiology and the North American Society of Pacing and Electrophysiology, Circulation. 93 (5), 1043 (1996).

82. E. Z. Golukhova, A. M. Alieva, T. T. Kakuchaya, et al., Creat. Cardiol. 1, 76 (2009).

83. S. S. Il'ina, A. S. Cherneev, I. P. Efimova, N. E. Umanskaya, and V. V. Zapara, Vestn. Orenburg Gos. Univ. 5, 115 (2005).

84. I. V. Khmel'nitskii, V. I. Gorbachev, and S. M. Gorbacheva, Vestn. Anesthesiol. Resusc. 1, 53 (2016).

85. V. P. D'yakonov, Wavelets. From theory to practice (SOLON-Press, Moscow, 2008) [in Russian].

86. S. G. Kuklin, I. M. Mikhalevich, N. Yu. Rozhkova, et al., "New Information about Vibrational Transformations in the Cardiac Rhythm (Continuous Wavelet Analysis)," in Atlas of Temporal Variations of Natural, Anthropogenic and Social Processes (Yanus-K, Moscow, 2013), pp. 682-687 [in Russian].

87. F. X. Cepeda, M. Lapointe, C. O. Tan, and T. J. Andrew, Auton. Neurosci. 213, 1 (2018). https://doi.org/10.1016/j.autneu.2018.04.007

88. V. M. Uritskii and N. I. Muzalevskaya, Biomedical Informatics and Eniology (Problem, Results, Prospects) (Ol'ga, St. Petersburg, 1995), pp. 84-129 [in Russian].

89. V. S. Anishchenko, V. V. Astakhov, T. E. Vadivasova, et al., Prikl. Nonlin. Dynam. 3 (11), 190 (2003).

90. A. N. Kolmogorov and S. P. Novikov, Strange Attractor (Mir, Moscow, 1981) [in Russian].

91. B. B. Mandelbrot, The Fractal Geometry of Nature (Freeman, New York, 1982), Vol. 1.

92. Yu. P. Mukha and A. V. Bugrov, Volgograd NauchnoMed. Zh. 3 (19), 50 (2008).

93. A. V. Ardashev and A. Yu. Loskutov, Practical Aspects of Modern Methods of Analyzing Heart Rate Variability (MEDPRAKTIKA-M, Moscow, 2011) [in Russian].

94. I. L. Andreev and L. N. Nazarova, Prostranstvo Vremya, 1-2 (19-20), 414 (2015).

95. R. M. Baevskii, Klinich. Inform. Telemed. 1, 54 (2004).

96. D. Felice, C. Cafaro, and S. Mancini, Chaos 28 (3), 032101 (2018).

https://doi.org/10.1063/1.5018926
97. I. Prigogine and I. Stengers, Order Out of Chaos: Man's New Dialogue with Nature (Heinemann, London, 1984).

98. E. S. Bauer, Theoretical Biology (Akadémiai Kiadó, Budapest, 1967).

99. M. V. Vol'kenshtein, Biophysics (Nauka, Moscow, 1988) [in Russian].

100. H. Haken, Advanced Synergetics. Instability Hierarchies of Self-Organizing Systems and Devices (Springer, Berlin, 1983).

101. E. Schrödinger, What is Life? The Physical Aspect of the Living Cell (Cambridge University Press, 1944).

102. P. Glansdorff and I. Prigogine, Science 176 (4042), 1410 (1972).

103. A. I. Zotin, Thermodynamic Basis of the Reactions of the Organism to External and Internal Factors (Nauka, Moscow, 1988) [in Russian].

104. K. M. Lebedinskii, "Trends in the Development of Modern Anesthesiology," in Blood Circulation and Anesthesia, 2nd ed. (Chelovek, St. Petersburg, 2015), pp. 950-979 [in Russian].

105. E. A. Perez, The Universe Will Die of Cold. Boltzmann. Thermodynamics and Entropy (RBA Collecionables S.A., 2012).

106. C. Shannon, Works on Information Theory and Cybernetics (Inostrannaya Literatura, Moscow, 1963) [in Russian].

107. X. D. Zhang, Adv. Exp. Med. Biol. 1028, 39 (2017). https://doi.org/10.1007/978-981-10-6041-0_3

108. A. Porta, B. De Maria, V. Bari, A. Marchi, and L. Faes, IEEE Trans. Biomed. Eng. 64 (6), 1287 (2017). https://doi.org/10.1109/TBME.2016

109. C. Chen, Y. Jin, I. L. Lo, H. Zhao, B. Sun, Q. Zhao, et al., Int. J. Biol. Sci. 13 (10), 1320 (2017). https://doi.org/10.7150/ijbs.19462

110. V. I. Antonov, A. I. Zagainov, and A. N. Kovalenko, Nauchno-Tekh. Vedom. St. Petersburg Gos. Polytech. Univ. 6, 111 (2009).

111. A. Rényi, Probability Theory (North-Holland, Amsterdam, 1970).

112. S. P. Nosyrev, V. A. Grigor'ev, and A. N. Kovalenko, RF Patent No. 2226067 (2001).

113. PhysioNet-PhysioBank, https://www.physionet.org/physiobank/

114. D. A. Rand and L.-S. Young, Dynamical Systems and Turbulence, Lecture Notes in Mathematics (Springer, 1981), Vol. 898, pp. 366-381.

115. Ya. B. Danilevich, A. N. Kovalenko, and S. P. Nosyrev, Dokl. Biol. Sci. 429, 490 (2009). https://doi.org/10.1134/S0012496609060027

Translated by E. Kuznetsova 